PRÁTICAS CÊNICAS ACESSÍVEIS E A INTERAÇÃO ENTRE ARTISTAS COM E SEM DEFICIÊNCIA: UM BREVE OLHAR SOBRE O TRABALHO DOS ENCENADORES BOB WILSON E PIPPO DELBONO

Resumo

De modo a destacar uma possibilidade de cena acessível a partir da interação entre artistas com e sem deficiência, o artigo lança um breve olhar sobre o trabalho de dois grandes expoentes da cena teatral contemporânea, Robert Wilson e Pippo Delbono. Trajetórias, procedimentos de criação e perspectivas éticas e estéticas do trabalho dos encenadores são cotejados, informando sobre as relações entre os artistas e suas influências na cena através da problematização da competência e de padrões normalizadores.

Palavras-chave:

Cena acessível. Pessoa com deficiência. Criação cênica. 


\title{
PRÁTICAS CÊNICAS ACESSÍVEIS E A INTERAÇÃO ENTRE AR- TISTAS COM E SEM DEFICIÊNCIA: UM BREVE OLHAR SOBRE 0 TRABALHO DOS ENCENADORES BOB WILSON E PIPPO DELBONO
}

\author{
Marcia Berselli (UFSM)' \\ Marta IsaAcSSON (UFRGS) ${ }^{2}$
}

\footnotetext{
${ }^{1}$ Professora do Departamento de Artes Cênicas da Universidade Federal de Santa Maria. Doutoranda junto ao Programa de Pós-Graduação em Artes Cênicas da Universidade Federal do Rio Grande do Sul. E-mail: marcia. berselli@ufsm.br.

${ }^{2}$ Profa. Dra. Titular da Universidade Federal do Rio Grande do Sul onde atua no ensino da graduação e pós-graduação de Artes Cênicas. Sócia fundadora da Associação Brasileira de Pesquisa e Pós-Graduação (ABRACE), tendo presidido a mesma entidade no período de 20112012. Desde 2008, é bolsista produtividade de pesquisa CNPq, atualmente PQ $1 \mathrm{~B}$. E-mail: missilva@portoweb. com.br.
}

De modo a refletir sobre a participação de artistas com e sem deficiência na cena contemporânea, propomos lançar um olhar sobre o trabalho de dois artistas cuja trajetória, consolidada no teatro, permite observar atravessamentos e reverberações de tal participação nas suas criações. Assim, buscaremos reconhecer características dos trabalhos de dois encenadores contemporâneos, Robert Wilson e Pippo Delbono, a partir de suas relações criativas com artistas com deficiência. A análise dos dois encenadores fornece pontos importantes para a compreensão de modos possíveis da ampliação do acesso de artistas com deficiência à cena contemporânea, a partir de perspectivas estéticas e políticas diversas. Além disso, tal aproximação pode nos indicar uma transformação no olhar sobre a deficiência, tirando de foco as limitações e privilegiando as potências que o encontro criativo com a diferença pode promover.

Antes de iniciar a aproximação aos expoentes, vale destacar que a cena concentra o poder de representar, espelhar 
ou tensionar as construções sociais. Enquanto parte da cultura, o "teatro expressa a sociedade em que ocorre através de uma ampla gama de sistemas culturais [...] contribuindo com suas normas e regras, expressando seus signos e significados" (FISCHER-LICHTE, 1997, p.25, trad. nossa). Assim, as representações de modelos corporais e os significados atribuídos aos atributos físicos nas artes da cena contribuem para as construções sociais que determinam padrões de habilidade e eficiência. Kirsty Johnston (2016) problematiza a representação da deficiência na dramaturgia teatral moderna, destacando como a deficiência é performada quando, por exemplo, associada a um desvio moral sinalizado através de uma marca corporal. Essa representação pode facilmente ser vinculada ao modelo médico da deficiência, aquele no qual a deficiência é intrínseca, privilegiando a ideia da ausência de algo, de necessidade de cura ou reabilitação. Em oposição ao modelo médico, a abordagem do modelo social da deficiência começou a ganhar impulso a partir da década de 1960, identificando a deficiência como um aspecto de interação entre a pessoa e o ambiente ${ }^{3}$. Dessa forma, ampliar o acesso às artes cênicas diz respeito não só à presença em cena de pessoas com deficiência, mas a uma provocação de alargamento do olhar sobre a deficiência na sociedade contemporânea.

\section{Outras possibilidades de comunicação: $o$ atrito entre canal visual e sonoro em Robert Wilson}

Robert Wilson inicia sua carreira profissional nos anos 60 em Nova York. Depois de graduar-se em 1965 no Pratt Institute of Art, Wilson trabalhou com pessoas com deficiências físicas e mentais.

Eu trabalhei com crianças hiperativas e com danos cerebrais. Então eu comecei a trabalhar com pessoas que respiravam artificialmente, muitos dos quais eram catatônicos. Fui contratado para fazer com que os pacientes falassem. O diretor do hospital achou importante que os pacientes se comunicassem uns com os outros e com a equipe. Eu trabalhei lá por dois anos, e no final daquele tempo eu cheguei à conclusão que não era necessário tentar incentivar aquelas pessoas a falar. Eu trabalhei com crianças pré-escolares em Harlem, com pessoas idosas em Nova Jersey, e com pacientes em instituições mentais. Em todas essas classes eu não estava lá para ensinar nada, mas para ouvir para descobrir no que eles estavam interessados e ajudá-los a fazer o que eles queriam fazer. (WILSON apud HOLMBERG, 2004, p.3, trad. nossa).

No relato de Wilson é possível observar um modo de trabalho determinante na relação com as pessoas com deficiência, e que estará presente na sua trajetória: o foco do encenador não estava concentrado em ensinar um modo padrão de comunicação, mas em estabelecer espaços de expressão de acordo com os interesses e possibilidades de cada sujeito. Segundo Galizia (1986) foi o contato com a Sra. Byrd Hoffman - bailarina que havia auxiliado Wilson a corrigir um problema de linguagem - que estimulou Bob Wilson às práticas com pessoas com deficiências, além de abrir "as portas de uma nova visão das artes teatrais" (GALIZIA, 1986, p.22). Foram os métodos da Sra. Hoffman que pontuaram seus cursos de expressão e sensibilização corporal, oferecidos também a crianças com deficiências.

Paralelamente a seu trabalho com catatônicos, pessoas com deficiência física e crianças com lesões cerebrais, Robert Wilson organizou, no final dos anos sessenta, oficinas de movimento onde a lentidão era usada para forçar suavemente as resistências dos participantes para despertar sua sensibilidade. Como bom professor respeitoso com os outros, ele começa a encorajar cada um a se tornar consciente de sua individualidade corporal, a desenvolver livremente o seu vocabulário pessoal e a implementar um movimento comum, por

\footnotetext{
${ }^{3}$ No modelo social, um usuário de cadeira de rodas fica incapacitado quando, por exemplo, encontra apenas escadas para acessar um local específico. Para maior aprofundamento, consultar MCDONNELL, P. Deficiência, surdez e ideologia no final do século XX e início do século XXI. Educação \& Realidade, Porto Alegre, v. 41, n. 3, p. 777-788, jul./set. 2016. doi: https://doi.org/10.1590/2175-623661091.
} 
exemplo a rotação, em um ritmo e com variações singulares. (MAURIN, 2010, p. 25-6, trad. nossa).

Em fins de 1967 Wilson começa a apresentar performances na Fundação Byrd Hoffman. A Fundação, uma organização sem fins lucrativos localizada em Nova Iorque, apresentava como objetivo principal "o desenvolvimento de oficinas de dança, teatro, cinema e artes aplicadas para crianças e adultos" (GALIZIA, 1986, p.24). Participavam das atividades promovidas pela Fundação pessoas com deficiências físicas ou mentais, bem como pessoas sem deficiência, de variadas idades. Através de workshops de movimento e consciência corporal, Bob Wilson criou suas primeiras peças, com um grupo chamado os Byrds (HOLMBERG, 2004).

"Não era apenas um tempo de cena de relaxamento e pausa, mas um meio de aumentar o conhecimento do corpo e autocontrole. A velocidade de execução pode, então, acelerar, a dificuldade dos exercícios aumentar, permitindo a redescoberta dos corpos e das possibilidades de comunicação através de outros canais que os verbais." (MAURIN, 2010, p. 26, trad. nossa).

Além de trabalhar como professor, Wilson também exerceu a função de coordenador da Fundação. Ainda segundo Galizia, citando um excerto de um relatório da Fundação Byrd Hoffman, as oficinas buscavam "estimular seus membros a tornarem-se mais conscientes de seus próprios corpos e das maneiras pelas quais estes interagem com os outros corpos que os rodeiam" (GALIZIA, 1986, p.26). Colocar os participantes em relação parece ser um dos interesses de Wilson, promovendo possibilidades de interações entre os sujeitos de modo a favorecer o desenvolvimento de competências e capacidades. Os procedimentos utilizados, no sentido de estimular a auto expressão e as potencialidades de cada sujeito a partir de suas possibilidades, reforça o interesse de Wilson em estabelecer uma relação com cada sujeito a partir de seus próprios modos de ação e comunicação, sem a imposição de formas:
[...] como professor e, mais tarde, presidente da Byrd Hoffman Foundation, Wilson deixava claro seu propósito de organizar situações em que pessoas com diferentes interesses, experiências e capacidades pudessem se encontrar, estimulando nelas o desenvolvimento da individualidade, em vez da transmissão de informações em áreas específicas do conhecimento. (PEREIRA, 2008, p. 120).

Com o enfoque na individualidade, observamos que os padrões determinados de normalidade não encontram espaço no trabalho de Wilson, não há comparação ou o interesse em uma determinada formatação da expressão dos participantes. Para além do enquadramento das pessoas em um modelo de movimento, o encenador está interessado em promover espaços de relação nos quais as pessoas se sintam encorajadas a criativamente explorar suas possibilidades. Nesse encontro, não só os participantes desenvolvem conhecimentos específicos, mas o próprio Wilson passa a encontrar outros modos de articulações de movimento, tempo e espaço.

As práticas com crianças com deficiência influenciaram as criações de Bob Wilson, em trabalhos com ênfase no poder das imagens e na comunicação não verbal. "Estou profundamente comprometido com o trabalho corporal. Este comprometimento originou-se quando de meu trabalho com crianças deficientes, em que utilizei a atividade física como método para sensibilizar o corpo e estimular a percepção" (WILSON apud GALIZIA, 1986, p.27). Dois encontros específicos potencializaram essa influência: primeiro, com Raymond Andrews, surdo, e posteriormente com Christopher Knowles, autista. Os pontos de vista e desenhos de Raymond Andrews foram a inspiração para Deafman Glance (O olhar do surdo - 1971). Nesse espetáculo, os signos não são organizados de modo a possibilitar leituras padronizadas; em uma multiplicidade de sons e imagens, os códigos não são facilmente decifrados e nem há uma lógica causal entre as ações, características essas que serão uma constante nos espetáculos de Wilson. Já Christopher Knowles participará de diversas criações em colaboração com Bob 
Wilson ${ }^{4}$ o qual afirma que:

[...] uma das mais profundas influências sobre meu trabalho foi o meu encontro, em 1967, com Raymond Andrews, uma criança afro-americana surdo-muda de treze anos de idade. Depois de um longo processo, eu poderia adotá-lo. Meu primeiro trabalho importante para o teatro foi escrito com ele. Era curioso, muitas vezes ele via coisas que eu não via, preocupado que eu estava em ouvi-lo. Ele percebia os gestos, os movimentos dos olhos, uma língua que eu não estava ciente. As primeiras peças escritas com Raymond foram silenciosas. Mais tarde, em 1973, eu conheci Christopher Knowles, uma criança autista de quatorze anos que fazia colagens sonoras em fitas. Eu consegui que ele pudesse vir morar comigo. A influência de Chris foi tão impressionante quanto a de Raymond. (WILSON, 1997, s/p, trad. nossa).

No contato com percepções diferenciadas da imagem e da palavra, o encenador encontra alimento criativo para suas proposições cênicas. $\mathrm{O}$ encontro com Raymond Andrews o faz perceber o pensamento formado por meio de imagens, e não apenas por palavras. "Ele fez desenhos para se comunicar comigo, e eu percebi que ele pensava em imagens. Essa experiência provou para mim o quanto a mente depende do pensamento visual" (WILSON apud HOLMBERG, 2004, p.79, trad. nossa). Nesse encontro, o encenador relaciona o trabalho corporal que já vinha desenvolvendo - nas oficinas e workshops que facilitava - com o desenvolvimento da linguagem corporal de Andrews, levando os dois à criação do espetáculo Deafman Glance. É interessante perceber como desse encontro singular nasce uma potência criativa para a cena.

Conhecer um jovem com deficiência - Raymond Andrews, um adolescente afro-americano surdo - foi o ponto crítico na carreira de Wilson. Andando por uma rua em Summit, New Jersey, em 1968, Wilson viu um policial espancar um garoto de doze anos sobre a cabeça com um porrete. $\mathrm{O}$ garoto estava fa- zendo sons estranhos e inarticulados. Wilson interveio e acompanhou o oficial e o menino à delegacia. Mais tarde, ele descobriu que o menino morava em dois quartos com doze outros membros da família e tinha sido declarado ineducável. Wilson adotou a criança para tentar educá-lo. Como se vê, a criança também educou Wilson. "Ele começou a fazer desenhos para me mostrar várias coisas que eu não iria notar e que ele seria mais sensível a notar por causa de sua surdez. Então eu percebi que ele pensava, não em palavras, mas em sinais visuais" (Quartet). Wilson explorou a linguagem corporal de Raymond em oficinas; surdos contam muito com movimento para se comunicar. De Raymond, Wilson aprendeu quão sutil e sofisticada a linguagem corporal pode ser. Essas explorações culminariam em Deafman Glace - uma peça sem palavras baseada nos desenhos que Raymond fez para se comunicar com Wilson. (HOLMBERG, 2004, p.3, trad. nossa).

Por outro lado, Christopher Knowles o leva à compreensão da potência da palavra enquanto produtora de sons e criadora de um ambiente sonoro através de jogos linguísticos. Ou seja, características específicas dos contextos, repertórios e modos de comunicação desses dois colaboradores influenciam o trabalho do encenador, que identifica e passa a reconhecer esses códigos quando da interação com Andrews e Knowles. Levando essas propostas para o processo de criação, a encenação, assim, também se transforma em um modo de comunicação diferenciado, por meio do destaque aos elementos visuais e sonoros. A influência das práticas realizadas com a Sra. Byrd Hoffman, que auxiliaram Wilson com sua dificuldade de fala, reverbera em suas criações. $O$ trabalho com jogos linguísticos, as possibilidades de jogo com intensidades sonoras e rítmicas se fazem presentes na trajetória do encenador. Holmberg aponta o teatro de Wilson como uma crítica à língua. Se a literatura e a filosofia criticam a língua sendo, porém, limitadas pelo próprio código que criticam, o teatro tem a possibilidade de utilizar outros canais de comunicação, e é isso

\footnotetext{
${ }^{4}$ Em colaboração com Knowles, Bob Wilson vai escrever diversos textos, iniciando uma fase de seu trabalho em que a palavra é utilizada de forma diferenciada, através do uso de repetições, variações rítmicas, e desmembramento.
} 
que Wilson faz em seu teatro, utilizando signos visuais para questionar as palavras e colapsar a linguagem (HOLMBERG, 2004).

$O$ interesse pela palavra e sua relação com o som podem ser vislumbrados em diversos momentos da trajetória de Bob Wilson. Em colaboração, Wilson e Knowles desenvolveram também uma série de performances - "peças-diálogo" -, jogos de palavras e sons. O uso da linguagem verbal pode ser apresentado enquanto marco da segunda fase do trabalho do encenador. Holmberg apresenta quatro períodos da carreira de Wilson, organizadas em "óperas silenciosas" (primeiro período), "desconstruindo a linguagem" (segundo período), "da semiótica à semântica" (terceiro período) e "como fazer coisas com palavras" (quarto período) (HOLMBERG, 2004, p.2). É a partir desta divisão que Holmberg vai discorrer sobre o trabalho de Bob Wilson. O primeiro período, segundo o autor, culmina em 1973 com The Life and Times of Joseph Stalin. É nesse momento que Wilson conhece Christopher Knowles, que participa de uma cena do espetáculo iniciando as colaborações entre os dois.

O modo de se comunicar, a organização matemática das palavras e sons interessavam particularmente a Wilson. "Eu não o conhecia, mas fiquei intrigado com a fita [com uma uma poesia de Knowles]. Fiquei ainda mais maravilhado quando o conheci e percebi o que ele fazia com a linguagem [...] Ele estava sempre redefinindo códigos" (WILSON apud GALIZIA, 1986, p.27). São esses modos que vão influenciar Wilson no trabalho com o texto, que passa a ser utilizado como mais um elemento versátil da encenação. Desse encontro, é a qualidade sonora, em tempos, ritmos, tamanhos das palavras, que passarão a ser centro de interesse, e não o significado do texto. No trabalho com Andrews e Knowles as relações com a palavra ganham importância central no teatro de Wilson, porém mobilizando a palavra da hierarquia tradicional por ela ocupada no teatro, e transformando sua função na comunicação (MAURIN, 2010).

Para Maurin (2010), no contato com esses sujeitos, Bob Wilson parece encontrar um outro sistema de percepção sensorial, outra estruturação do espaço e do tempo que aponta às qualidades da imagem e do ritmo. $\mathrm{O}$ jogo entre canal visual e canal sonoro denota a busca por uma experiência sensorial diferenciada no trabalho de Wilson, que marca sua estética a partir da fricção, do atrito entre dois sistemas de representação: o visual e o sonoro. Há um afastamento da imagem enquanto ilustração do texto, assim como do movimento que enfatiza o texto falado/cantado. "Ambos os canais estão progredindo em paralelo na arquitetura do todo, cada um perseguindo sua linha sem considerar o outro" (MAURIN, 2010, p.143, trad. nossa). Esse desejo de tensionamento de elementos é alimentado no encontro com os artistas com deficiência, e Wilson busca que todos os colaboradores possam ser mutuamente influenciados.

"Enquanto uma terapia tradicional busca reeducá-los, ele toma ao contrário suas deficiências como padrão e pratica uma espécie de contra terapia que preserva essa deficiência, a integra, a encoraja ao oposto das normas sociais. Ele o neutraliza subtraindo-o de um diagnóstico clínico e o valoriza colocando-o no centro de seu trabalho artístico. E os membros da trupe imitam Raymond Andrews ou Christopher Knowles, e não o contrário, para ajustar-se à sua sensibilidade, para aprender seus movimentos palpitantes como andar para frente e para trás ou balançando. Gradualmente, a lentidão deixa seu status como uma ferramenta terapêutica e/ou sintoma patológico para qualificar um ritmo estético por direito próprio: um tempo rubato." (MAURIN, 2010, p. 26/7, grifo do autor, trad. nossa).

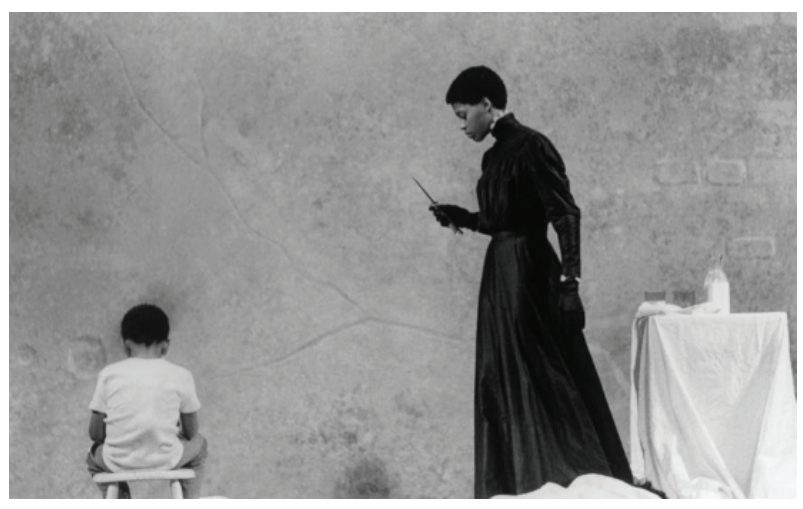

Fig. 1: Deafman Glance (O olhar do surdo). Disponível em www.robertwilson.com 
Para Wilson, é o interesse em modos diversos de percepção, diferentes do cotidiano, que promove uma aproximação com as diferenças. No trabalho com pessoas com deficiência, com formas de comunicação e relação com o outro e com o espaço diferenciadas, suas intenções teatrais são potencializadas e o encenador encontra maneiras de explorar estas questões plasticamente. É a encenação, a organização visual e sonora de elementos em cena que interessam a Bob Wilson, não um trabalho terapêutico.

Isso explica a negação virulenta que Robert Wilson opõe às alegações banais que fazem dele, pelo menos em seus primeiros espetáculos, de um encenador-terapeuta: 'Eu odeio a terapia!' De seu trabalho com deficientes físicos e mentais não permanece mais que uma plástica temporal, uma linguagem metafórica que tenta entre outras dar conta da lentidão incomum de seu teatro. Que os gestos parecerão autistas não significa que eles são gestos de autista, nem que a catalepsia visual represente uma visão de catalepsia clínica. (MAURIN, 2010, p.27, trad. nossa)

$\mathrm{Na}$ relação criativa estabelecida com os artistas com deficiência, modos de percepção diferenciados - que informam sobre modos de ser/estar no mundo - são compreendidos e levados para a cena. $\mathrm{O}$ artista é o ser que tem a capacidade de perceber a vida de forma diferenciada, e é isso que faz Wilson reconhecer as capacidades de seus colaboradores, que apresentam um modo de percepção e de expressão diferenciados do comum. A encenação de Wilson busca despertar o espectador para essas qualidades perceptivas traduzidas em imagens e sons. O artista traduz, através de um encadeamento entre os elementos da encenação, uma percepção que nasce nele a partir do encontro com diferentes modos de interação com o exterior, mobilizando, dessa forma, os padrões convencionados de modos de leitura do mundo. Estando atento aos seus colaboradores e buscando entendê-los em suas singularidades e não através de modos tradicionais, Bob Wilson respeita suas diferenças e são esses fatores que o levam a reestruturação do teatro (HOLMBERG, 2004).

Esses modos diversos de percepção não são identificados apenas nos trabalhos que nascem da parceria de Bob Wilson com artistas com deficiência, mas reverberam marcando um estilo de encenação de Wilson, que explora e utiliza toda a potência de uma relação singular com as imagens, sons e movimentos, modificando os modos de dar sentido ao que é visto/ ouvido pelo espectador e que certamente tem relação com a trajetória do encenador e suas primeiras experimentações na Fundação Byrd Hoffman - tanto na relação com as pessoas com deficiência quanto na aproximação com a dança a partir das práticas da bailarina Byrd Hoff$\operatorname{man}^{5}$.

Um exemplo claro pode ser reconhecido analisando o processo de criação de Wilson, com a utilização dos visual books. Semelhante aos storyboards da produção cinematográfica, os visual books são criados apresentando imagens visuais em sequência de cada momento significativo da peça. Bob Wilson começa a trabalhar na perspectiva dos storyboards em Einstein on the Beach, espetáculo que estreou em 1976 (INNES; SHEVTSOVA, 2013). Os visual books seriam como os textos escritos da literatura dramática, mas aqui em uma versão da escritura cênica, auxiliando na construção da trajetória do espetáculo enquanto um roteiro e um guia, e servindo ainda como uma forma de notação da criação mantendo uma memória do material criado. Com os visual books reconhecemos um modo de operar visualmente na criação cênica, no qual pensamentos e ideias são concretizados e externalizados em imagens. O modo de operar no processo de criação através de imagens está relacionado certamente a sua formação enquanto arquiteto, seu repertório enquanto pin-

5 “"...] he has never stopped thinking of his work as dance, the most corporeal, in-the body art of them all. And the principle of dance affects all the elements that he uses to such an extent that nothing is ever quite static, not even objects, let alone light, that moving light which has made him a light designer unparalleled among peers" (SHEVTSOVA, 2007, p. 46). 
tor e escultor, mas, também, ao encontro com Raymond Andrews.

Wilson transforma a relação entre significado e significante explorando a potência que nasce da ampliação da percepção quando algo é dado a ver/ouvir de modo diverso. Essa ampliação ocorre nas palavras encadeadas de modo a romper com o sentido cotidiano ou com o que seria imediatamente reconhecido - como é o caso das explorações sonoras fruto de seu trabalho com Knowles - na potência da utilização das imagens e códigos visuais em detrimento da palavra - observada em parcerias com Andrews. As características destacadas parecem mobilizar o imaginário dos espectadores, que são convocados não apenas a contemplar o que está sobre a cena, mas a habitar, momentaneamente, um universo diverso do cotidiano. Bob Wilson organiza signos na cena sem estar interessado em determinar seus significados, estes dependem da interação com o espectador, convocado a elaborar sentidos a partir de sua relação com a obra.

Assim, o encontro com Andrews e Knowles parece potencializar um desejo latente em Wilson: formas diferenciadas de percepção transformadas em modos de comunicação por diferentes vias, outras que não um modo tradicional. Há, nessa forma de comunicação, a necessidade do engajamento dos sentidos não para atingir uma compreensão, mas para que a cena convoque o espectador. É necessária uma troca no teatro de Wilson: a cena oferece elementos, e o espectador se engaja no sentido de ser invadido pelo que é oferecido e lidar ele próprio com esses elementos que lhe chegam. As formas de interação, os modos de relacionar elementos do exterior e do interior, diferenciados em Andrews e Knowles pelas suas características específicas, são fomentadores para o que Wilson tem interesse de colocar em cena. Há um elemento importante nesta relação que diz respeito à interação diretor e performer. Se- gundo Galizia:

É através da interação entre diretor e performer e não pela imposição que os ritmos da comunicação podem ser desencadeados. Mas embora Wilson estimule no performer a descoberta de sua própria linguagem, ele também ressalta o fato de que o processo de interação entre duas pessoas (diretor e performer, performer e performer, ou performer e espectador) é algo que independe do significado em si das palavras ou gestos utilizados. Segundo Wilson, há um elemento na linguagem que precede o significado e que torna a comunicação possível, uma espécie de energia. [...] Convencido de que a comunicação pode ser eficiente neste nível, Wilson insiste em que o diretor e o performer, dois indivíduos cujas 'linguagens' são diferentes, devem encontrar-se 'no meio do caminho'. Cada um deve fazer um esforço para entender a 'linguagem' do outro em termos de ritmos e estruturas a fim de ser bem-sucedido. (GALIZIA, 1986, p. 76 77).

Tal característica reconhecida por Galizia nos indica sobre a importância do contato entre a pessoa com e sem deficiência na criação. Não se trata da perspectiva de um se impondo sobre a do outro, mas da aproximação de modos de recepção diversos, que, na interação criativa, vão reverberar em uma estética e uma poética específicas.

\section{Pippo Delbono: os repertórios individuais e a sinceridade na atuação}

O encenador italiano Pippo Delbono inicia seus estudos de arte dramática nos anos 80, em uma escola tradicional, a Scuola di Teatro della Provincia di Savona. Delbono deixa a escola para seguir com Pepe Robledo, ator argentino, para a Dinamarca onde se juntam a um grupo liderado por Iben Nagel Rasmussen.

Estive três anos trabalhando sobre a arte do ator. Um trabalho não psicológico, mas sobre

\footnotetext{
${ }^{4}$ Prótese do grego $\pi \rho o ́ \sigma \theta \varepsilon \sigma ı \varsigma$ (adição): equipamento para substituição de partes ausentes no corpo (dentária, membros superiores e inferiores, ocular, auditiva). Órtese: equipamento para correção de partes do corpo afetadas por paralisias, síndromes, má formação, acidentes, lesões na coluna dentre outros (coletes, botas ortopédicas etc.).
} 
a consciência, sobre a ludicidade do estar em cena. O training foi a experiência mais importante. Usar o corpo e a voz, dançar no silêncio por muito tempo e aprender os princípios que são dramáticos - o ritmo, suas transformações, a direção no espaço, a perda de equilíbrio, os saltos, as quedas, a dança dos olhos todos princípios físicos, não psicológicos. No training você se exercita para se tornar uma espécie de guerreiro lúcido e atento. (DELBONO, 1999, p. 28, trad. nossa).

Assim se inicia sua busca por uma nova linguagem teatral. Delbono se dedica ao estudo dos princípios do teatro oriental, e em 1987 em parceria com Robledo cria Il tempo degli assassini. Em 1987 também é convidado a participar de um ano de trabalho no Wuppertal Tanztheater de Pina Bausch. O encontro é um marco no percurso do ator e diretor. Em entrevista, Delbono comenta sobre seu interesse no teatro não tradicional e a influência dos encontros ocorridos:

Eu comecei estudando e fazendo um teatro tradicional, depois, um pouco casualmente, comecei a seguir experiências no mundo que me emocionavam mais, que me davam alguma coisa mais importante, e assim fui estudar na Dinamarca. Trabalhei no Odin, trabalhei com Pina Bausch, ou seja, segui experiências importantes de professores. Não professores convencionais, mas mestres de grande importância. Um teatro não tradicional, mas de grande técnica e conhecimento teatral e não simplesmente um teatro não tradicional. (MASSA; WEBER, 2001, p. 60).

Em 1989 Pippo Delbono descobre ser soropositivo. Segundo Pereira (2008), este fato o leva a uma percepção diferenciada do corpo, fator que influenciará seu trabalho futuro. Um momento decisivo de sua trajetória artística acontece em 1996, quando o grupo está desenvolvendo um workshop em um manicômio de Aversa. Durante as atividades, alguns internos observam o trabalho desenvolvido, e é nesse contexto que se dá o encontro com Bobò, como é chamado Vincenzo Cannavacciuolo.
Bobò é um homenzinho surdo-mudo, analfabeto, encontrado (em ocasião de uma atividade laboratorial) no manicômio de Aversa, onde estava internado por 45 anos. Pippo reconhece em Bobò e na sua capacidade gestual os princípios do teatro oriental. Os elementos que Pippo havia desenvolvido depois de longos anos de treinamento estavam presentes como dote adquirido em Bobò, um ator capaz de acompanhar com precisão seu gesto teatral na ausência total de retórica ${ }^{6}$.

Desse encontro é criado o espetáculo Barboni, no qual Bobó é protagonista. Nesse período Delbono conhece Armando Cozzuto, que vivia pela Praça San Domenico Maggiore, em Nápoles. Armando, que sofrera poliomielite e utilizava muletas para se deslocar, encorajava Delbono que na época sofria de fortes dores nas pernas. Ele passa a frequentar os ensaios, e em um determinado dia comenta com Delbono que "o sofrimento ensina o amor e isso as muletas o haviam ensinado" (DELBONO, 1999, p. 68, trad. nossa). Pippo Delbono pede que ele repita a frase na cena, fato que marca sua entrada na companhia. Um pouco depois, Delbono convida para participar da criação Mr. Puma, Gianni Briano, hiperativo. $\mathrm{O}$ encontro com pessoas que vivem à margem da sociedade e a possibilidade de colocar em cena pessoas diferentes com histórias de vida singulares estimula no diretor o interesse por um teatro não tradicional e não psicológico. É, então, no processo de criação de Barboni que pessoas sem experiência teatral, e advindas de diversos contextos, passam a integrar a companhia de Delbono.

Mais tarde, no espetáculo Guerra (1998), iriam juntar-se Nelson Lariccia um ex- desabrigado de aspecto nobre e Gianluca Ballarè, um rapaz down ex-aluno da mãe de Pippo, que o havia apresentado ao filho diretor. Delbono não reconhece por trás do rótulo de ' $\mathrm{Te}$ atro Social' o motivo da escolha desses atores, porque eles são considerados entre os mais capazes e hábeis a encarnar sua visão poética de um teatro baseado em pessoas e não em personagens, um teatro não psicológico, evi-

\footnotetext{
${ }^{6}$ Biografia Pippo Delbono. Disponível em: <<http://www.pippodelbono.it/biografia-pippo-delbono.html >>. Acesso em 21 jan. 2016, trad. nossa.
} 
tando os clichês ensinados nas escolas e nas academias. $^{7}$

Para Pippo Delbono, Barboni nasce a partir do encontro com Bobó e um profundo desejo de liberdade, sem ideias intelectuais prévias. Diferente de Bob Wilson, Pippo Delbono se interessa mais pelas características particulares dos artistas com deficiência colocadas em cena. São suas histórias, seus modos de relacionar suas deficiências em atrito com padrões estabelecidos que alimentam as encenações. Reconhecemos assim um aspecto que distingue os dois encenadores. No encontro com pessoas com deficiência, é a possibilidade poética de cada um que interessa a Pippo Delbono. Enquanto que em Bob Wilson o encontro alimenta o encenador através do atrito de elementos pelos modos de percepção e relação sensorial, o encenador italiano aponta seu interesse pela sinceridade na atuação dos artistas que não interpretam, mas "são" no palco, no sentido de se exporem efetivamente, honestamente. Suas histórias de vida e modos de relação com o mundo são apresentados em cena. Delbono vê qualidades específicas nestes sujeitos, qualidades artísticas que têm a ver com o contexto de origem e modo de vida. É a inocência, a sinceridade sobre o palco que interessa ao diretor. Assim, encontramos outro ponto de convergência entre o trabalho dos encenadores: os modos diferenciados de percepção, que em Bob Wilson servem como alimento para as criações que posteriormente ganharão forma na cena, e que em Pippo Delbono são colocados em cena a partir de seus próprios agentes.

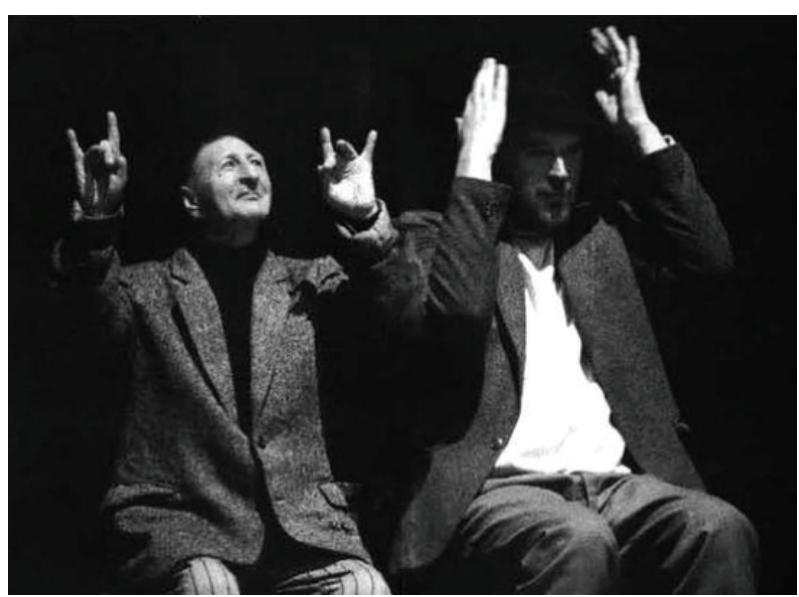

Fig. 2: Barboni. Disponível em www.pippodelbono.it

Porém, assim como Wilson, Delbono não reconhece seu trabalho como terapia, nem mesmo vincula as criações com os colaboradores ao modelo médico da deficiência ${ }^{8}$. "Quando observo Ginaluca ou Bobò ou Nelson em sua grande liberdade, eles não me parecem por nada deficientes, podem viver um relacionamento direto com suas alegrias, com seus sofrimentos sem mediação, são pessoas livres" (DELBONO, 1999, p. 71-72, trad. nossa).

As histórias de vida e a identidade construída a partir da relação dos criadores com suas deficiências são motes de criação para os processos de Delbono. Assim, os repertórios individuais dos sujeitos são convocados, e as diversas situações vividas, a partir de seus diferentes contextos, ganham espaço na cena. Quando das criações, "é solicitado aos atores que apresentem suas descobertas mais recentes, ainda que fora do tema proposto para a peça. Escolhidos e isolados, os gestos e ações tornam-se sequenciais, compondo uma estrutura descolada de qualquer psicologia” (PEREIRA, 2008, p. 161). Esses artistas não têm formação artística específica, e Delbono parece se interessar pelo que eles podem oferecer para a cena a partir de seus cotidianos, de quem eles são enquanto sujeitos. Tal

\footnotetext{
${ }^{7}$ Ibid.

${ }^{8}$ Conforme apresentado no início do artigo, a abordagem que evidencia a falha e o problema a ser corrigido através de intervenção médica é justamente o modelo médico de deficiência.
} 
fato é uma das características que exerce atração sobre Delbono. Para o encenador, é o que eles têm de genuíno, em suas figuras, o mais interessante para suas cenas.

Com um repertório de treinamento físico aprofundado, a partir de seu trabalho com os princípios formativos da Antropologia Teatral do Odin Teatret, pelo viés de Iben Nagel Rasmussen, o training, Ghiglione questiona Delbono sobre o atrito entre o imaginário acerca desse treino físico, que remete a um corpo atlético, quase perfeito e os corpos diversos dos atores que trabalham em sua companhia. A esta pergunta, o encenador responde que:

Certamente o training pode se tornar mais uma gaiola de virtuosismo. Em todos esses anos fui levado ao encontro de pessoas que no teatro trazem vida. Pessoas com corpos diversos: gordos, magérrimos, desajeitados, rígidos, pesados, mas extremamente poéticos. E descobri que algumas dessas pessoas tinham dentro de si naturalmente os signos de uma linguagem primordial. Em seus gestos, em seus movimentos estão os princípios dramáticos: por exemplo introduzindo a suspensão em momentos de máxima tensão, as mudanças bruscas de ritmo que produzem uma grande concentração no seu corpo de ator e grande atenção no espectador. (DELBONO, 1999, p. 30, trad. nossa)

Como exemplo, Delbono cita uma cena do espetáculo Guerra, em que Bobò leva um cavalinho de madeira e o acaricia. Neste momento, para o encenador, o corpo de Bobò é um conjunto de contrastes, de oposições físicas que capturam a atenção do espectador. A intensidade do gesto do ator é comparada por Delbono aquela que, no teatro oriental e em sua própria trajetória inicial com o training, é resultado de um extenso treinamento (DELBONO, 1999). Pippo Delbono tem um interesse particular pelas qualidades expressivas dos diferentes criadores com os quais trabalha. Percebendo nos artistas com deficiência, conforme o exemplo citado, a presença de determinadas qualidades buscadas nas artes da cena, e que nestes sujeitos parecem ser "naturais", como a sabedoria do gesto de Bobó. Tais características derrubam as convenções dos atores, fato que leva Delbono a dizer que seus atores são seus mestres.

Quando estou no palco sou como guiado pelas suas presenças, essas pessoas têm ritmo, você tem que ouvir o seu corpo, estar aberto, para ter um relacionamento verdadeiro com o que eles fazem. Bobò é um mestre do teatro, ele precisa experimentar as coisas se divertindo como se fosse a primeira vez, e mesmo em cena ele também está com a realidade das coisas concretas e então para trabalhar com ele é preciso clareza, simplicidade, verdade. Bobò é absolutamente sincero no que ele faz porque seu corpo não pode mentir. Há pessoas que têm uma verdadeira relação com a vida e com o sofrimento e sobre a cena seus gestos são sinceros. (DELBONO, 1999, p. 71, trad. nossa).

Assim, Delbono trabalha sobre a personalidade dos atores, suas histórias e experiências, e não a partir da ideia de personagens. Pippo Delbono também reconhece no processo de criação o diálogo entre "dois mundos": o seu e o do ator. "No momento da construção de um espetáculo, o seu imaginário de ator converge para o meu mundo de encenador. É sempre um diálogo entre o meu mundo e aquele do ator da companhia" (DELBONO, 1999, p. 31, trad. nossa). Conforme anteriormente destacado sobre o trabalho de Robert Wilson, aqui também observamos a perspectiva da interação, do contato entre percepções diferenciadas, marcadas pela distinção e respeito pelas singularidades.

\section{Conclusões parciais}

No trabalho dos dois expoentes, percebemos a presença do artista com deficiência alimentando as criações a partir de suas características, como elementos diferentes que desestabilizam o modo cotidiano e promovem a possibilidade de outros modos de ação, uma peculiaridade do teatro que está em constante busca do agir diferente do tradicional e do que já se tornou padrão. São justamente as diferenças, e não o enquadramento em um padrão de normalidade, que despertam o interesse dos encenadores aqui analisados. $\mathrm{Na}$ contramão 
de propostas normalizadoras, há uma aproximação entre as práticas de criação de Wilson e Delbono com os artistas com deficiência: são a diversidade e as formas múltiplas de relação individual com o mundo que interessam, que os alimentam criativamente. $\mathrm{O}$ contato com os colaboradores com deficiência desloca o núcleo de artistas para modos de ver, ouvir e movimentar diferenciados, impulsionando dessa forma o processo de criação.

Com a aproximação às trajetórias e propostas dos dois encenadores apresentados, é possível reconhecer algumas características que podem promover práticas cênicas acessíveis. Identificamos, assim: o distanciamento da perspectiva dramática, o não psicologismo, a presença de elementos apresentados pelos colaboradores a partir de seus contextos e leituras de mundo servindo como motes de criação - de modo mais direto no trabalho de Delbono, por outro lado alimentando principalmente o olhar de encenador em Bob Wilson - e o aspecto relacional a partir do modo de interação entre os colaboradores envolvidos no processo. A interação diz respeito ao contato contínuo entre os colaboradores, pressupondo a criação de um entre-dois, um espaço que não destaca exclusivamente singularidades, mas que configura a diversidade a partir da articulação dos aspectos que diferenciam cada sujeito. Antes de isolar as características dos sujeitos, abrindo espaço para que significados estáticos se consolidem - tais como aqueles que informam sobre o que seja deficiência - se enfatiza que tais significados sempre têm lugar na relação com o outro.

Nesse sentido, nos expoentes destacados a interação foi observada especificamente entre as funções de encenador e ator. A partir da relação de troca estabelecida entre o sujeito que atua e aquele que, de modo geral, é o responsável pela consolidação de uma estética - a partir da reunião de todos os materiais na composição da cena -, observamos a importância da colaboração contínua, no processo criativo, entre pessoas com e sem deficiência. A colaboração reforça que o processo criativo pode ser formativo para todos os envolvidos, sem que se anulem os repertórios particulares, mas encontrando na diferença e distinção benefícios e desafios, sem privilegiar um conceito categorizante que toma o outro como uma determinada representação. A interação entre artistas com e sem deficiência no processo criativo promove a possibilidade de uma contribuição à cena que se centra na troca entre as diversidades, quando aspectos criativos se materializam a partir do contato entre os colaboradores. O aprofundamento no estudo das características observadas no trabalho de Pippo Delbono e Robert Wilson é tema para a continuação de nossas investigações, e esperamos que as perspectivas aqui apresentadas possam também impulsionar outras pesquisas que se debrucem sobre práticas cênicas acessíveis. Sendo o teatro um espaço de convívio social, o tema apresenta extrema relevância na busca por uma sociedade efetivamente inclusiva. 


\section{REFERÊNCIAS}

DELBONO, Pippo. Il viaggio, la guerra, il volo. Conversazione com Pippo Delbono a cura di Alessandra Rossi Ghiglione. Separata de GHIGLIONE, Alessandra Rossi. Barboni Il teatro di Pippo Delbono. Milano: Ubulibri, p. 17-89, 1999.

FISCHER-LICHTE, Érika. The show and the gaze of theatre: a European perspective. Iowa: University of Iowa Press, 1997. 426p.

GALIZIA, Luiz Roberto. Os processos criativos de Robert Wilson. São Paulo: Editora Perspectiva, 1986. 207p.

HOLMBERG, Arthur. The theatre of Robert Wilson. Cambridge: Cambridge University Press, 2004. 229p.

INNES, Christopher; SHEVTSOVA, Maria. The Cambridge introduction to theatre directing. New York: Cambridge University Press, 2013. 298p.

JOHNSTON, Kirsty. Disability Theatre and Modern Drama. London/New York: Bloomsbury, 2016. 241p.

MASSA, Clóvis; WEBER, Suzane. Do esterco nasce a flor. Cena, Porto Alegre, RS, ano 2, n. 2, p. 59-62, 2001. Entrevista.

MAURIN, Frédéric. Robert Wilson: le temps pour voir, l'espace pour écouter. Paris: ActesSud, 2010.

PEREIRA, José A. T. R. O teatro das disfunções ou a cena contaminada. 2008. $200 \mathrm{f}$. Tese (Doutorado em Teatro) - Centro de Letras e Artes, Universidade Federal do Estado do Rio de Janeiro, Rio de Janeiro, 2008.

SHEVTSOVA, Maria. Robert Wilson. London \& New York: Routledge, 2007. $288 \mathrm{p}$.

WILSON, Robert. Entretien avec Robert Wilson. Résonance, n. 11, Ircam - Centre Georges Pompidou. Paris, janvier, 1997. Disponível em <http://articles.ircam. fr/textes/Ircam97b/>. Acesso em 13 jan. 2016. 


\begin{abstract}
In order to highlight a possibility of accessible scene from the interaction between artists with and without disabilities, the article takes a brief look at the work of two great exponents of the contemporary scene, Robert Wilson and Pippo Delbono. Trajectories, creative procedures and ethical and aesthetic perspectives of the work of the directors are collated, informing about the relations between the artists and their influences in the scene through the problematization of competence and normalizing standards.
\end{abstract}

\title{
Keywords
}

Accessible scene. Disabled person. Scenic creation.

\section{Resumen}

Para destacar una posibilidad de escena accesible a partir de la interacción entre artistas con y sin discapacidad, el artículo lanza una breve mirada sobre el trabajo de dos grandes exponentes de la escena teatral contemporánea, Robert Wilson y Pippo Delbono. Las trayectorias, procedimientos de creación y perspectivas éticas y estéticas del trabajo de los directores son cotejados, informando sobre las relaciones entre los artistas y sus influencias en la escena a través de la problematización de la competencia y de estándares normalizadores.

\section{Palabras clave}

Escena asequible. Persona con discapacidad. Creación escénica. 